\title{
Retrospective analysis of risk factors for postoperative perineal hernia after endoscopic abdominoperineal excision for rectal cancer
}

Tatsuya Manabe ${ }^{1 *}$, Yusuke Mizuuchi ${ }^{2}$, Yasuhiro Tsuru' ${ }^{1}$, Hiroshi Kitagawa', Takaaki Fujimoto', Yasuo Koga', Masafumi Nakamura ${ }^{2}$ and Hirokazu Noshiro ${ }^{1}$

\begin{abstract}
Background: In contrast to open-surgery abdominoperineal excision (APE) for rectal cancer, postoperative perineal hernia (PPH) is reported to increase after extralevator APE and endoscopic surgery. In this study, therefore, we aimed to determine the risk factors for PPH after endoscopic APE.

Methods: A total 73 patients who underwent endoscopic APE for rectal cancer were collected from January 2009 to March 2020, and the risk factors for PPH were analyzed retrospectively.

Results: Nineteen patients (26\%) developed PPH after endoscopic APE, and the diagnosis of PPH was made at 9-393 days (median: 183 days) after initial surgery. Logistic regression analysis showed that absence of pelvic peritoneal closure alone increased the incidence of PPH significantly (odds ratio; 13.76, 95\% confidence interval; 1.481884.84, $p=0.004$ ).
\end{abstract}

Conclusions: This preliminary study showed that pelvic peritoneal closure could prevent PPH after endoscopic APE. Keywords: Postoperative perineal hernia, Endoscopic abdominoperineal excision, Rectal cancer

\section{Background}

Postoperative perineal hernia (PPH) after abdominoperineal excision (APE) of the rectum is a complication caused by herniation of the intra-abdominal organs through the pelvic floor after complete removal of the anorectal sequence. Although most PPHs after APE are asymptomatic or ignorable, some patients have serious symptoms such as discomfort, perineal pain, impaired sensation, urinary dysfunction or intestinal obstruction when perineal bulging is gradually enlarged $[1,2]$.

\footnotetext{
*Correspondence: manabe@cc.saga-u.ac.jp

1 Department of Surgery, Faculty of Medicine, Saga University, 5-1-1

Nabeshima, Saga 849-8501, Japan

Full list of author information is available at the end of the article
}

Therefore, some patients have disturbed quality of life and others require surgical treatment. In patients with conventional open APE, the incidence of clinically manifest PPH was reported as $<1 \%[3,4]$ and PPH based on barium X-rays was 7\% [5]. However, recent technical modifications in APE for rectal cancer are associated with increased incidence of PPH. One such modification is extralevator APE (ELAPE) for rectal cancer, which involves wide resection of the levator ani muscles surrounding the rectum through two-phase abdominal and perineal resection to obtain sufficient circumferential resection margins and prevent inadvertent rectal rupture [6]. Despite the improved oncological outcomes, increased perineal complications have been reported after removal of excessive pelvic tissue in ELAPE, 
compared with conventional APE [7-10]. To prevent $\mathrm{PPH}$, therefore, exact pelvic reconstruction, such as the myocutaneous flap method or use of a biological mesh, has been performed after ELAPE [6, 11, 12]. In contrast, endoscopic surgery is associated with reduced incidence of ventral hernia after colorectal surgery [13], but an increased incidence of PPH after endoscopic APE has been reported [9]; thus, some preventive procedure against $\mathrm{PPH}$ is advocated.

In previous studies, risk factors for PPH after conventional open APE included previous hysterectomy, perineal wound infection, perioperative radiotherapy, coccygectomy, excessive length of small bowel mesentery, and larger size of the female pelvis [3, 14-17]. However, most of these reports were from small studies or case reports, and the risk factors for PPH after endoscopic APE for rectal cancer are not well documented until now. In this study, we conducted retrospective analysis to clarify the incidence and risk factors for PPH after endoscopic APE for rectal cancer.

\section{Methods}

A total of 75 patients with rectal cancer underwent endoscopic APE with simple closure of the perineum at Saga University Hospital or the Department of Surgery and Oncology in Kyushu University Hospital between January 2009 and March 2020. Patients who underwent total pelvic exenteration were excluded. $\mathrm{PPH}$ was defined as an obvious bulge in the perineum and/or downward displacement of the intestine beyond the line described by computed tomography from the inferior margin of the pubis to the end of the coccyx (Fig. 1). Standard surveillance using computed tomography was routinely carried out every 6 months for at least 5 years after surgery, and irregularly performed to investigate other disease, based on the physician's decision.

The demographics of the patients were obtained from the prospectively maintained comprehensive database and medical records. The tumor stage was classified according to the eighth TNM classification system. Patients with clinical T4, pelvic nodal involvement and/ or circumferential resection margin $<1 \mathrm{~mm}$ by magnetic resonance imaging received preoperative chemoradiotherapy and/or systemic chemotherapy. Postoperative systemic chemotherapy was administered to patients with pathologically positive lymph nodes and/or distant metastases. Patient-related variables, tumor-related variables, therapeutic variables and postoperative variables were investigated to clarify the risk factors for $\mathrm{PPH}$.

\section{Ethics}

All procedures in this study were conducted in accordance with the ethical standards of the responsible

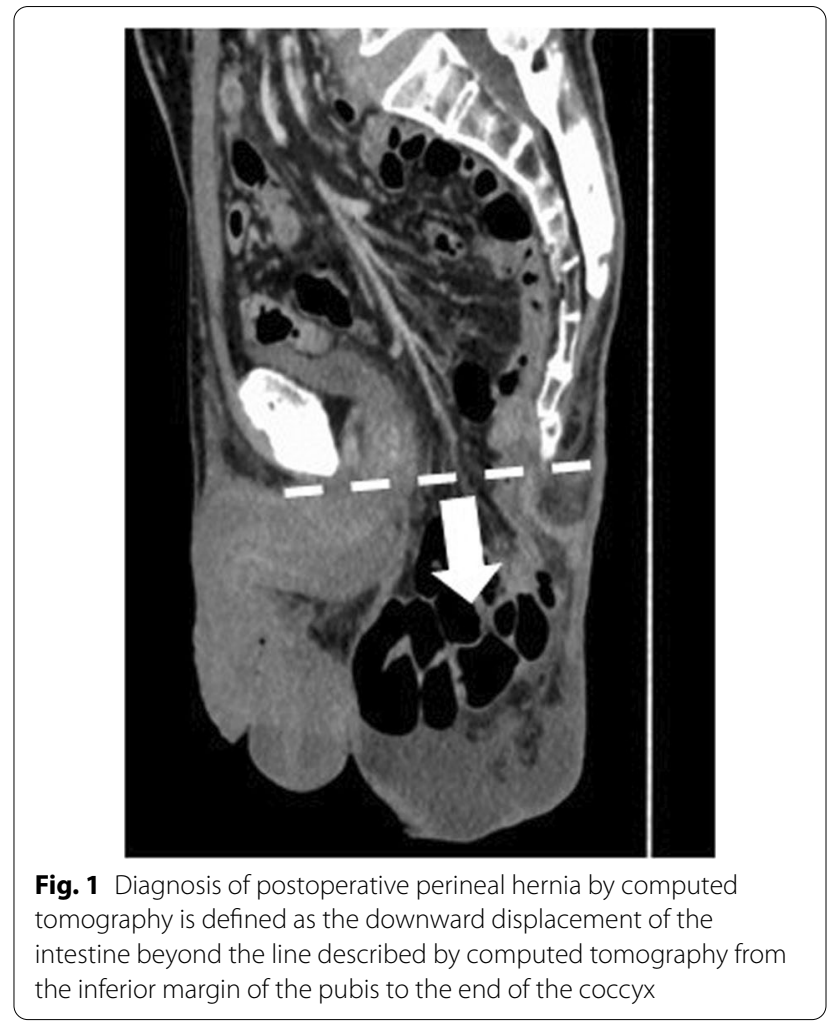

committee on human study and with the Helsinki Declaration and later revision. The demographics of the patients were obtained from the prospectively maintained comprehensive database and the medical records. Informed consent for the use of medical information was obtained from all patients. The study protocol was approved by the Ethics Committee of the Faculty of Medicine at Saga University (2019-09-Jinsoku-03) and Kyushu University (29-292).

\section{Endoscopic APE}

All patients were placed in the supine modified LloydDavies position. Laparoscopic surgery was performed using a five-port technique: a supra-umbilical port for the laparoscope, two ports at the right lower quadrant, and two ports placed symmetrically at the left lower quadrant. For robot-assisted APE using the da Vinci $\mathrm{Si}$ Surgical System (Intuitive Surgical Inc., Sunnyvale, CA, USA), six ports were placed as described previously [18]. Typically, after ligation of the inferior mesenteric artery, mobilization of the rectum with total mesorectal excision (TME) preserving the autonomic nerves was performed in the pelvis along the presacral space. Posterior dissection in the TME plane stopped at the apex of the coccyx. Next, the lateral ligaments were divided bilaterally and the peritoneal reflection was opened, and the anterior side of the rectum was dissociated to the lower edge of 
the prostate for men, or along the rectovaginal septum for women. The levator ani muscle was divided transabdominally from the posterior to lateral side to the ischiorectal fossa. When endoscopic transperineal TME was performed, vascular ligation and dissection of the upper rectum were laparoscopically performed and the levator ani muscle was divided via the perineal approach. Finally, the specimen was extracted through the perineal wound. Closure of the perineum was performed by primary approximation of the skin and subcutaneous tissue. PPC was added for some patients. After specimen removal, the pelvic peritoneum was closed neatly with interrupted 3-0 Vicryl sutures from the anterior to posterior under laparoscopic vision and/or using robotic arms (Fig. 2). The choices of surgical approach, route of the stoma, and PPC depended on the discretion of the treating surgeon.

\section{Statistical analysis}

All statistical analyses were performed using JMP version 14 (SAS Institute, Cary, NC, USA). For descriptive analysis, continuous variables were compared between the groups by the Mann-Whitney U test, while the chisquared test and analysis of variance were used for comparison of categorical variables. For univariate analysis, simple logistic regression analysis was used. Multiple logistic regression analysis with Firth correction was performed to identify factors that were independently associated with PPH. $p<0.05$ was considered to be statistically significant.

\section{Results}

Patient, tumor, therapeutic and postoperative characteristics are summarized in Table 1 . Median observation period was 963 days (range 9-2190 days). Of all 73

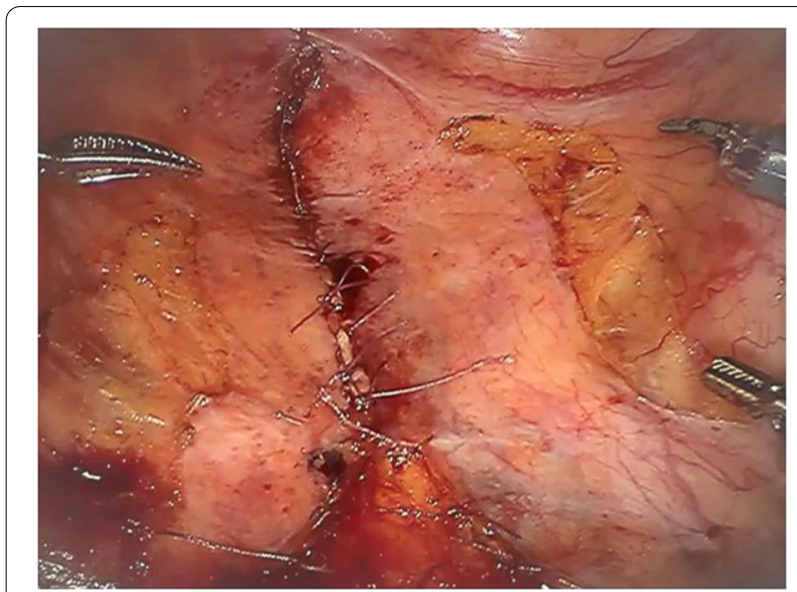

Fig. 2 Endoscopic view of pelvic peritoneal closure with shallow incision patients who underwent endoscopic APE for rectal cancer, 19 (26\%) developed PPH. Three of these 19 patients received hernia repair for the severe symptoms. The cumulative incidence of $\mathrm{PPH}$ is shown in Fig. 3. The median period of detection of $\mathrm{PPH}$ was 183 days (range 9-393 days) after surgery. PPH did not occur in any patient $>2$ years after surgery.

Table 2 shows the results of univariate analysis. No patient-related, tumor-related or postoperative variables were associated with PPH. Among therapeutic variables, preoperative therapy, surgical approach, performance of transperineal endoscopic approach, addition of pelvic lymph node dissection, route of the stoma, operating time, blood loss volume, transfusion residual tumor, and postoperative systemic chemotherapy were not associated with PPH. PPC alone was significantly associated with the incidence of PPH $(p=0.012)$. Multivariate logistic regression analysis with Firth correction that included PPC and postoperative perineal wound dehiscence was performed to identify independent factors associated with occurrence of PPH. PPC was independently associated with the occurrence of PPH (odds ratio $=13.757$, $95 \%$ confidence interval $=1.484-1884.838 ; p=0.004)$ (Table 3).

\section{Discussion}

This study showed that PPH occurred in $26 \%$ of patients with endoscopic APE for rectal cancer within 13 months after surgery and that PPC was available for prevention of $\mathrm{PPH}$. The importance of PPC for preventing perineal complications was advocated by McMullin [4] and Goliger [19] in 1985. In conventional open APE, PPC is a standard procedure when sufficient peritoneal tissue is preserved [20]. Similarly, Yan et al. [21] reported that no PPH was found in 86 cases that underwent endoscopic APE with additional PPC, and that the incidence of PPH was significantly lower in endoscopic APE with than without PPC ( $0 \%$ vs $5.21 \%, p=0.032)$. Nevertheless, the pelvic peritoneum is often not closed during endoscopic APE because laparoscopy is necessary for proficient suturing [22, 23]. In contrast to the previous reports about the risk factors for PPH [3, 14-17], this study did not show that PPH had any correlation with female sex, preoperative radiotherapy, or multiple organ resection including coccygectomy. Measurement of the mesenteric length was not accessible under the laparoscopic approach.

Although PPC is a useful technique to prevent PPH, some discussion remains before performing PPC. First, the peritoneum must be removed widely to avoid division of the mesorectum during medial and lateral dissection of the upper rectum from the pelvis under laparoscopy. When it is hard to perform peritoneal 
Table 1 Patient and Clinical Characteristics

\begin{tabular}{|c|c|c|c|c|}
\hline \multirow[t]{3}{*}{ Parameters } & \multirow[t]{3}{*}{ Total (n) } & \multicolumn{2}{|l|}{ Perineal hernia } & \multirow[t]{3}{*}{$p$ value } \\
\hline & & Presence & Absence & \\
\hline & & $\mathrm{n}=19$ & $\mathrm{n}=54$ & \\
\hline \multicolumn{5}{|l|}{ Patient-related variables } \\
\hline \multicolumn{5}{|l|}{ Age } \\
\hline Median (range) & & $66(42-89)$ & $68(31-86)$ & 0.472 \\
\hline \multicolumn{5}{|l|}{ Sex } \\
\hline Male & 49 & 11 & 38 & 0.325 \\
\hline Female & 24 & 8 & 16 & \\
\hline \multicolumn{5}{|l|}{$\mathrm{BMI}^{*}\left(\mathrm{~kg} / \mathrm{m}^{2}\right)$} \\
\hline Median (range) & & $20.3(17.9-34.8)$ & $21.5(15.9-33.8)$ & 0.991 \\
\hline \multicolumn{5}{|l|}{ ASA-PS** } \\
\hline 1 & 15 & 6 & 9 & 0.404 \\
\hline 2 & 54 & 12 & 42 & \\
\hline 3 & 4 & 1 & 3 & \\
\hline \multicolumn{5}{|l|}{ Tumor-related variables } \\
\hline \multicolumn{5}{|l|}{ Depth of the tumor } \\
\hline pT1 & 5 & 0 & 5 & 0.344 \\
\hline pT2 & 19 & 5 & 14 & \\
\hline pT3 & 40 & 10 & 30 & \\
\hline pT4b & 7 & 3 & 4 & \\
\hline$C R$ & 2 & 1 & 1 & \\
\hline \multicolumn{5}{|c|}{ Maximum diameter of tumor (mm) } \\
\hline Median (range) & & $47(0-116)$ & $44(0-280)$ & 0.173 \\
\hline \multicolumn{5}{|c|}{ Site of inferior margin of the tumor } \\
\hline Upper rectum & & 0 & 2 & 0.387 \\
\hline Lower rectum & & 15 & 36 & \\
\hline Anal canal & & 4 & 16 & \\
\hline \multicolumn{5}{|c|}{ Simultaneous distant metastasis } \\
\hline Yes & 7 & 1 & 6 & 0.431 \\
\hline No & 66 & 18 & 48 & \\
\hline \multicolumn{5}{|l|}{ Therapeutic variables } \\
\hline \multicolumn{5}{|l|}{ Preoperative therapy } \\
\hline \multicolumn{5}{|l|}{ Total } \\
\hline Yes & 21 & 7 & 14 & 0.373 \\
\hline No & 62 & 12 & 40 & \\
\hline \multicolumn{5}{|l|}{ NCRT*** } \\
\hline Yes & 9 & 4 & 5 & 0.200 \\
\hline No & 64 & 15 & 49 & \\
\hline \multicolumn{5}{|l|}{ Systemic chemotherapy } \\
\hline Yes & 15 & 4 & 11 & 0.950 \\
\hline No & 58 & 15 & 43 & \\
\hline \multicolumn{5}{|l|}{ Surgical approach } \\
\hline Endoscopic surgery & 56 & 14 & 42 & 0.738 \\
\hline Robot-assisted surgery & 8 & 3 & 5 & \\
\hline Trans-perineal approach & 9 & 2 & 7 & \\
\hline \multicolumn{5}{|l|}{ Multivisceral resection } \\
\hline Yes & 7 & 3 & 4 & 0.308 \\
\hline No & 66 & 16 & 50 & \\
\hline
\end{tabular}


Table 1 (continued)

\begin{tabular}{|c|c|c|c|c|}
\hline \multirow[t]{3}{*}{ Parameters } & \multirow[t]{3}{*}{ Total (n) } & \multicolumn{2}{|c|}{ Perineal hernia } & \multirow[t]{3}{*}{$p$ value } \\
\hline & & Presence & Absence & \\
\hline & & $\mathrm{n}=19$ & $n=54$ & \\
\hline \multicolumn{5}{|c|}{ Lateral pelvic lymphnode dissection } \\
\hline Yes & 37 & 9 & 28 & \multirow[t]{2}{*}{0.737} \\
\hline No & 36 & 10 & 26 & \\
\hline \multicolumn{5}{|l|}{ Route of stoma } \\
\hline Transperitoneal route & 51 & 14 & 37 & \multirow[t]{2}{*}{0.670} \\
\hline Retroperitoneal route & 22 & 5 & 17 & \\
\hline \multicolumn{5}{|l|}{ Pelvic peritoneal closure } \\
\hline Yes & 11 & 0 & 11 & \multirow[t]{2}{*}{0.007} \\
\hline No & 62 & 19 & 43 & \\
\hline \multicolumn{5}{|l|}{ Operating time (min) } \\
\hline Median (range) & & $553(276-850)$ & $671(281-1089)$ & 0.256 \\
\hline \multicolumn{5}{|l|}{ Bleeding (g) } \\
\hline Median (range) & & $210(0-940)$ & $232(0-1267)$ & 0.799 \\
\hline \multicolumn{5}{|l|}{ Transfusion } \\
\hline Yes & 10 & 2 & 8 & \multirow[t]{2}{*}{0.632} \\
\hline No & 63 & 17 & 46 & \\
\hline \multicolumn{5}{|l|}{ Residual tumor } \\
\hline $\mathrm{RO}^{\#}$ & 66 & 17 & 49 & \multirow[t]{3}{*}{0.732} \\
\hline $\mathrm{R}^{\# \#}$ & 2 & 1 & 1 & \\
\hline $\mathrm{R}^{\# \# \#}$ & 5 & 1 & 4 & \\
\hline \multicolumn{5}{|c|}{ Postoperative systemic chemotherapy } \\
\hline Yes & 33 & 7 & 26 & \multirow[t]{2}{*}{0.392} \\
\hline No & 40 & 12 & 28 & \\
\hline \multicolumn{5}{|l|}{ Postoperative variables } \\
\hline \multicolumn{5}{|c|}{ Postoperative complication } \\
\hline \multicolumn{5}{|c|}{ Perineal wound dehiscence } \\
\hline Yes & 8 & 4 & 4 & \multirow[t]{2}{*}{0.120} \\
\hline No & 65 & 15 & 50 & \\
\hline \multicolumn{5}{|l|}{ Pelvic abscess } \\
\hline Yes & 9 & 1 & 8 & \multirow[t]{2}{*}{0.240} \\
\hline No & 64 & 18 & 46 & \\
\hline \multicolumn{5}{|l|}{ Urinary disorder } \\
\hline Yes & 12 & 3 & 9 & \multirow[t]{2}{*}{0.929} \\
\hline No & 61 & 16 & 45 & \\
\hline Ileus & & & & \\
\hline Yes & 9 & 2 & 7 & 0.778 \\
\hline No & 64 & 17 & 47 & \\
\hline Length of postoperative & & & & \\
\hline Median (range) & & $17(8-66)$ & $18(5-75)$ & 0.898 \\
\hline
\end{tabular}

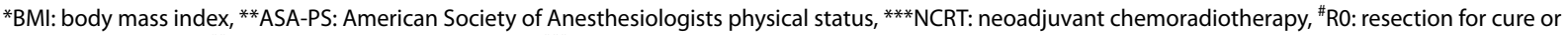
complete remission, ${ }^{\# R}$ 1: microscopic residual tumor, \#\# R2: macroscopic residual tumor

closure because of severe tension, addition of a shallow incision on the tense portion of the peritoneum could be helpful to relax it [21]. During suturing of the peritoneum, the stitching intervals should be shortened, because herniation of the intestine through the unexpected defect of the closed peritoneum could occur. Indeed, we did not observe herniation because interrupted stitches were placed at short intervals during peritoneal closure. Next, high proficiency is mandatory in suturing procedures by conventional 


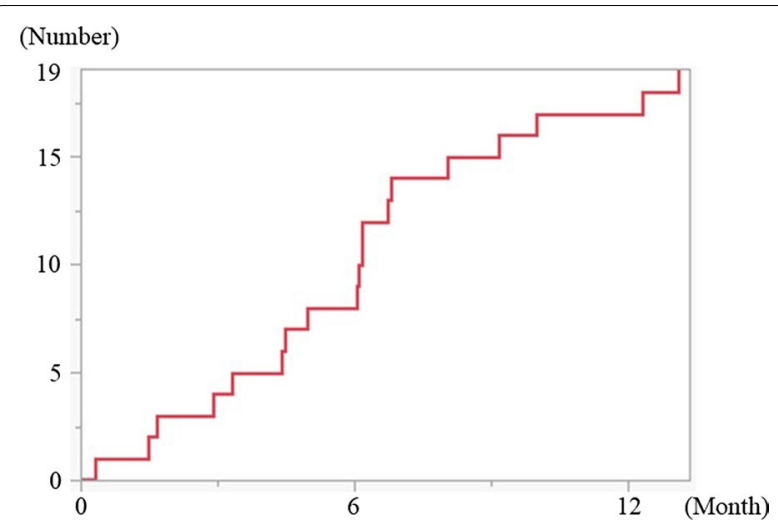

Fig. 3 Cumulative number of patients with postoperative perineal hernia after endoscopic abdominoperineal excision

laparoscopic surgery. Robotic surgery might facilitate such procedures. Finally, PPC could not be performed in some patients with endoscopic APE because of tumor invasion to the pelvic peritoneum, bulky tumor, addition of lateral pelvic lymph-node dissection, and preoperative chemoradiotherapy [24].

Various pelvic reinforcements as alternatives to PPC have been performed after APE: suture of levator ani muscle, bladder peritoneal flaps, hysteropexy, omentoplasty and synthetic mesh. Levator ani muscle suturing [25] could not be applied to rectal cancer surgery because of wide excision of the muscle. A randomized trial revealed that omentoplasty did not reduce the incidence of PPH [26]. Several studies have revealed that Bio-mesh can be effective for reducing PPH [10, 12, 27]. Unfortunately, the use of Bio-mesh is limited to western countries. Immobilization of bladder peritoneal flaps in men and the uterus in women might be helpful for preventing $\mathrm{PPH}$, when PPC is impossible $[28,29]$.

The present study had some limitations: the retrospective design, small study population, and application of the approach for lateral pelvic lymph-node dissection and PPC was decided by surgeons. Therefore, this study data is preliminary, and a large number study would be needed to confirm this data.

\section{Conclusions}

This preliminary study suggested that the only risk factor for PPH was absence of PPC. Therefore, PPC could prevent PPH after endoscopic APE for rectal cancer. A further study is needed to confirm the risk factor for PPH.
Table 2 Univariate analysis to evaluate the risk factors for postoperative perineal hernia

\begin{tabular}{|c|c|c|}
\hline Parameters & OR $(95 \% \mathrm{Cl})$ & $p$ value \\
\hline \multicolumn{3}{|l|}{ Patient-related variables } \\
\hline Age & $1.016(0.974-1.059)$ & 0.467 \\
\hline \multicolumn{3}{|l|}{ Sex } \\
\hline Male/Female & $0.5789(0.1962-1.7081)$ & 0.325 \\
\hline $\mathrm{BMI}^{*}$ & $1.0009(0.8558-1.1706)$ & 0.991 \\
\hline \multicolumn{3}{|l|}{ ASA-PS** } \\
\hline $1 / 2$ & $2.3333(0.6916-7.8719)$ & 0.172 \\
\hline $1 / 3$ & $2.0000(0.1662-24.0689)$ & 0.585 \\
\hline $2 / 3$ & $0.8571(0.0816-9.0087)$ & 0.898 \\
\hline \multicolumn{3}{|l|}{ Tumor-related variables } \\
\hline \multicolumn{3}{|l|}{ Depth of the tumor } \\
\hline$<\mathrm{pT} 2 />\mathrm{pT} 3$ & $0.7846(0.2575-2.3901)$ & 0.67 \\
\hline Maximum diameter of tumor ( $\mathrm{mm}$ ) & $0.9975(0.9821-1.0132)$ & 0.746 \\
\hline \multicolumn{3}{|l|}{ Site of inferior margin of the tumor } \\
\hline Rectum/Anal canal & $1.5479(0.4533-5.5003)$ & 0.473 \\
\hline Simultaneous distant metastasis & $0.4444(0.0500-3.9522)$ & 0.467 \\
\hline \multicolumn{3}{|l|}{ Therapeutic variables } \\
\hline \multicolumn{3}{|l|}{ Preoperative therapy } \\
\hline Total & $1.6667(0.5475-5.074)$ & 0.369 \\
\hline$N C R T^{* * *}$ & $2.6133(0.6214-10.9901)$ & 0.19 \\
\hline Systemic chemotherapy & $1.0424(0.2880-3.774)$ & 0.95 \\
\hline \multicolumn{3}{|l|}{ Surgical approach } \\
\hline Endoscopic/Robot & $0.5556(0.1175-2.6277)$ & 0.459 \\
\hline Endoscopic/Trans-perineal & $1.1667(0.2166-6.2840)$ & 0.858 \\
\hline Robot/Trans-perineal & $2.100(0.2507-17.5941)$ & 0.494 \\
\hline Multivisceral resection & $2.344(0.4735-11.6006)$ & 0.297 \\
\hline $\begin{array}{l}\text { Lateral pelvic lymphnode dissec- } \\
\text { tion }\end{array}$ & $0.8357(0.2934-2.3807)$ & 0.737 \\
\hline \multicolumn{3}{|l|}{ Route of stoma } \\
\hline Transperitoneal/Retroperitoneal & $1.286(0.3987-4.1514)$ & 0.673 \\
\hline Pelvic peritoneal closure & $3.2110(0.1029-3.6031)$ & 0.012 \\
\hline Operating time & $0.2071(0.0139-4.8280)$ & 0.245 \\
\hline Bleeding & $1.0002(0.9983-1.0023)$ & 0.794 \\
\hline Transfusion & $0.6765(0.1304-3.5095)$ & 0.642 \\
\hline \multicolumn{3}{|l|}{ Residual tumor } \\
\hline $\mathrm{RO} \# / \mathrm{R} 1^{\# \#}$ & $0.3469(0.0206-5.857)$ & 0.463 \\
\hline $\mathrm{RO} \# / \mathrm{R}^{\# \# \#}$ & $1.3878(0.1449-13.2948)$ & 0.776 \\
\hline 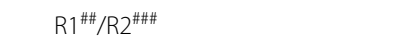 & $4.0000(0.1168-136.9573)$ & 0.442 \\
\hline $\begin{array}{l}\text { Postoperative systemic chemo- } \\
\text { therapy }\end{array}$ & $0.6282(0.2146-1.8391)$ & 0.396 \\
\hline \multicolumn{3}{|l|}{ Postoperative variables } \\
\hline \multicolumn{3}{|l|}{ Postoperative complication } \\
\hline Perineal wound dehiscence & $3.3333(0.7429-149571)$ & 0.122 \\
\hline Pelvic abscess & $0.3194(0.0372-2.7399)$ & 0.298 \\
\hline Urinary disorder & $0.9375(0.2253-3.9009)$ & 0.929 \\
\hline lleus & $0.7899(0.1492-4.1814)$ & 0.782 \\
\hline $\begin{array}{l}\text { Length of postoperative hospital } \\
\text { stay }\end{array}$ & $1.0025(0.9650-10415)$ & 0.897 \\
\hline
\end{tabular}

*BMI: body mass index, **ASA-PS: American Society of Anesthesiologists physical status, ${ }^{* * *}$ NCRT: neoadjuvant chemoradiotherapy, ${ }^{\#}$ RO: resection for 
Table 2 (continued)

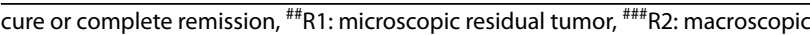
residual tumor

Table 3 Multiple logistic regression analysis with Firth correction to determine independent risk factors for Postoperative perineal hernia

\begin{tabular}{lcl}
\hline Parameters & OR $(\mathbf{9 5} \% \mathrm{Cl})$ & p value \\
\hline Peritoneal closure of the pelvis & $13.757(1.484-1884.838)$ & 0.004 \\
Perineal wound dehiscence & $0.211(0.034-1.042)$ & 0.057 \\
\hline
\end{tabular}

\section{Abbreviations}

APE: Abdominoperineal excision; PPH: Postoperative perineal hernia; PPC: Pelvic peritoneal closure; ELAPE: Extralevator APE; TME: Total mesorectal excision.

\section{Acknowledgements}

The authors thank Dr. Atsushi Kawaguchi of the Center for Comprehensive Community Medicine at the Faculty of Medicine of Saga University for his valued assistance in the statistical analyses of this study. We thank Cathel Kerr, BSc, PhD, from Edanz (https://jp.edanz.com/ac) for editing a draft of this manuscript.

\section{Authors' contributions}

TM was the main author of this article and performed the data collection and statistical analyses; YM, YT, HK, TF and YK contributed to the data collection; $\mathrm{MN}$ and $\mathrm{HN}$ contributed to the data collection and reviewed the manuscript; all authors have read and approved the final manuscript.

\section{Funding}

There was no funding for this study.

\section{Availability of data and materials}

The datasets used and analyzed during the current study available from the corresponding author on reasonable request.

\section{Declarations}

\section{Ethics approval and consent to participate}

All procedures in this study were conducted in accordance with the ethical standards of the responsible committee on human study and with the Helsinki Declaration and later revision. Informed consent for the use of medical information was obtained from all patients. The study protocol was approved by the Ethics Committee of the Faculty of Medicine at Saga University and Kyushu University.

\section{Consent for publication}

Participants gave their consent for publication.

\section{Competing interests}

The authors declare no conflicts of interest in association with the present study.

\section{Author details}

${ }^{1}$ Department of Surgery, Faculty of Medicine, Saga University, 5-1-1 Nabeshima, Saga 849-8501, Japan. ²Department of Surgery and Oncology, Graduate School of Medical Sciences, Kyushu University, 3-1-1 Maidashi, Higashi-ku, Fukuoka 812-8582, Japan.

Received: 10 October 2021 Accepted: 28 February 2022 Published online: 08 March 2022
References

1. Rajebhosale R, Miah M, Currie F, Thomas P. Closed loop obstruction and adhesive intestinal obstruction in perineal hernia. BMJ Case Rep. 2020. https://doi.org/10.1136/bcr-2020-238112.

2. Yasukawa D, Aisu Y, Kimura Y, Takamatsu Y, Kitano T, Hori T. Which therapeutic option is optimal for surgery-related perineal hernia after abdominoperineal excision in patients with advanced rectal cancer? A report of 3 thought-provoking cases. Am J Case Rep. 2018;19:663-8.

3. So JB, Palmer MT, Shellito PC. Postoperative perineal hernia. Dis Colon Rectum. 1997:40:954-7.

4. McMullin ND, Johnson WR, Polglase AL, Hughes ES. Post-proctectomy perineal hernia: case report and discussion. Aust NZJ Surg. 1985;55:69-72.

5. Hullsiek HE. Perineal hernia after abdominoperitoneal resection. Am J Surg. 1956;92:735-8.

6. Holm T, Ljung A, Häggmark T, Jurell G, Lagergren J. Extended abdominoperineal resection with gluteus maximus flap reconstruction of the pelvic floor for rectal cancer. Br J Surg. 2007;94:232-8.

7. West NP, Anderin C, Smith KJ, Holm T, Quirke P. Multicentre experience with extralevator abdominoperineal excision for low rectal cancer. Br J Surg. 2010;97:588-99.

8. Perdawood SK, Lund T. Extralevator versus standard abdominoperineal excision for rectal cancer. Tech Coloproctol. 2015;19:145-52.

9. Sayers AE, Patel RK, Hunter IA. Perineal hernia formation following extralevator abdominoperineal excision. Colorectal Dis. 2015;17:351-5.

10. Han JG, Wang ZJ, Gao ZG, Wei GH, Yang Y, Zhai ZW, Zhao BC, Yi BQ. Perineal wound complications after extralevator abdominoperineal excision for low rectal cancer. Dis Colon Rectum. 2019;62:1477-84.

11. Christensen HK, Nerstrøm P, Tei T, Laurberg S. Perineal repair after extralevator abdominoperineal excision for low rectal cancer. Dis Colon Rectum. 2011;54:711-7

12. Musters GD, Klaver CEL, Bosker RJI, Burger JWA, van Duijvendijk P, van Etten B, van Geloven AAW, de Graaf EJR, Hoff C, Leijtens JWA, Rutten HJT, Singh B, Vuylsteke RJCLM, de Wilt JHW, Dijkgraaf MGW, Bemelman WA, Tanis PJ. Biological mesh closure of the pelvic floor after extralevator abdominoperineal resection for rectal cancer: a multicenter randomized controlled trial (the BIOPEX-study). Ann Surg. 2017;265:1074-81.

13. Petersson J, Koedam TW, Bonjer HJ, Andersson J, Angenete E, Bock D, Cuesta MA, Deijen CL, Fürst A, Lacy AM, Rosenberg J, Haglind E, COlorectal cancer Laparoscopic or Open Resection (COLOR) II Study Group. Bowel obstruction and ventral hernia after laparoscopic versus open surgery for rectal cancer in a randomized trial (COLOR II). Ann Surg. 2019:269:53-7.

14. Kelly AR. Surgical repair of post-operative perineal hernia. Aust NZJ Surg. 1960;29:243-5.

15. Cawkwell I. Perineal hernia complicating abdominoperineal resection of the rectum. Br J Surg. 1963;50:431-3.

16. Frydman GM, Polglase AL. Perineal approach for polypropylene mesh repair of perineal hernia. Aust NZJ Surg. 1989;59:895-7.

17. Cattell RB, Cunningham RM. Postoperative perineal hernia following resection of rectum: report of a case. Surg Clin North Am. 1944:24:679-83.

18. Sakai Y, editor. Robotic total mesorectal excision. Laparoscopic surgery for colorectal cancer. The Netherlands: Springer; 2016.

19. Goliger J. Hernia: perineal. Surgery of the anus, rectum and Colon. 5th ed. London: Balliere Tindall; 1985. p. 701-2.

20. Peirce C, Martin S. Management of the perineal defect after abdominoperineal excision. Clin Colon Rectal Surg. 2016;29:160-7.

21. Yan X, Su H, Zhang S, Zhou L, Lu J, Yang X, Li J, Xue P, He Z, Wang M, Lu A, Ma J, Zang L, Cai Z, Sun J, Hong H, Zheng M, Feng B. Pelvic peritoneum closure reduces postoperative complications of laparoscopic abdominoperineal resection: 6-year experience in single center. Surg Endosc. 2021;35:406-14.

22. de Campos FG, Habr-Gama A, Araújo SE, Sousa AH Jr, Nahas CR, Lupinacc RM, Nahas SC, Kiss DR, Gama-Rodrigues J. Incidence and management of perineal hernia after laparoscopic proctectomy. Surg Laparosc Endosc Percutan Tech. 2005;15:366-70.

23. Wang YW, Huang LY, Song CL, Zhuo CH, Shi DB, Cai GX, Xu Y, Cai SJ, Li $X X$. Laparoscopic vs open abdominoperineal resection in the multimodality management of low rectal cancers. World J Gastroenterol. 2015:21:10174-83. 
24. Foster JD, Tou S, Curtis NJ, Smart NJ, Acheson A, Maxwell-Armstrong C, Watts A, Singh B, Francis NK. Closure of the perineal defect after abdominoperineal excision for rectal adenocarcinoma-ACPGBI position statement. Colorectal Dis. 2018;20(Suppl 5):5-23.

25. Ito E, Yoshida M, Ohdaira H, Kitajima M, Suzuki Y. Case series of in situ pelvic floor reconstruction combining levator ani suture and negative pressure wound therapy for abdominoperineal resection. Ann Med Surg (Lond). 2019;43:64-7.

26. Blok RD, Musters GD, Borstlap WAA, Buskens CJ, Bemelman WA, Tanis PJ, Collaborative Dutch Snapshot Research Group. Snapshot study on the value of omentoplasty in abdominoperineal resection with primary perineal closure for rectal cancer. Ann Surg Oncol. 2018;25:729-36.

27. Jensen KK, Rashid L, Pilsgaard B, Møller P, Wille-Jørgensen P. Pelvic floor reconstruction with a biological mesh after extralevator abdominoperineal excision leads to few perineal hernias and acceptable wound complication rates with minor movement limitations: single-centre experience including clinical examination and interview. Colorectal Dis. 2014:16:192-7.

28. Yang $X$, Jin C, Deng $X$, Wang $M$, Zhang $Y$, Wei M, Meng W, Wang Z. Laparoscopic extralevator abdominoperineal excision of the rectum with primary suturing: short-term outcomes from single-institution study. J Laparoendosc Adv Surg Tech A. 2016;26:40-6.

29. Yang T, Wei M, Deng X, Meng W, Wang Z. A novel laparoscopic technique with a bladder peritoneum flap closure for pelvic cavity for patients with rigid pelvic peritoneum after neoadjuvant radiotherapy in laparoscopic extralevator abdominoperineal excision. Dis Colon Rectum. 2019:62:1136-40.

\section{Publisher's Note}

Springer Nature remains neutral with regard to jurisdictional claims in published maps and institutional affiliations.

- fast, convenient online submission

- thorough peer review by experienced researchers in your field

- rapid publication on acceptance

- support for research data, including large and complex data types

- gold Open Access which fosters wider collaboration and increased citations

- maximum visibility for your research: over $100 \mathrm{M}$ website views per year

At BMC, research is always in progress.

Learn more biomedcentral.com/submissions 